04,09

\title{
Оптическая анизотропия фотонных кристаллов кубической симметрии, индуцированная многоволновой дифракцией света*
}

\author{
(C) Т.А. Уклеев ${ }^{1,2}$, Н.Н. Шевченко ${ }^{3}$, Д.И. Юрасова ${ }^{3}$, А.В. Селькин ${ }^{1,2}$ \\ ${ }^{1}$ Физико-технический институт им. А.Ф. Иофрфе, \\ 194021 Санкт-Петербург, Россия \\ ${ }^{2}$ Санкт-Петербургский государственный университет, \\ 199034 Санкт-Петербург, Россия \\ ${ }^{3}$ Институт высокомолекулярных соединений РАН, \\ 199004 Санкт-Петербург, Россия \\ E-mail: t.ukleev@gmail.com
}

\begin{abstract}
Экспериментально и теоретически изучены спектры брэгговского отражения света от опалоподобных фотонных кристаллов в условиях резонансного усиления многоволновой дифракции света. В качестве объектов исследования использованы фотонно-кристаллические структуры, изготовленные из монодисперсных глобул полистирола. Показано, что сигнал отражения, регистрируемый во взаимно ортогональных конфигурациях поляризатора и анализатора, связан с собственной оптической анизотропией кристалла и представляет собой специфическое проявление многоволновой брэгговской дифракции света в трехмерных фотонных кристаллах.
\end{abstract}

Работа подготовлена при поддержке программы президиума РАН № 7 „Актуальные проблемы фотоники, зондирование неоднородных сред и материалов“.

DOI: 10.21883/FTT.2018.05.45786.12D

\section{1. Введение}

Известно, что обычные кристаллы кубической симметрии по своим оптическим свойствам, как правило, изотропны (по крайней мере, в рамках классической кристаллооптики, когда не учитываются тонкие эффекты пространственной дисперсии) [1,2]. Этот факт тесно связан с возможностью описания общих оптических свойств кристаллов путем введения тензора диэлектрической проницаемости, не зависящего от пространственных координат. При этом характерный масштаб а неоднородности (например, размер постоянной решетки) должен быть существенно меньшим по отношению к длине волны $\lambda$ света. Однако в случае пространственно структурированных систем типа фотонных кристаллов (ФК), для которых $a \approx \lambda$, принципиальное значение имеет пространственная модуляция диэлектрической проницаемости $[3,4]$. Поэтому связь симметрии оптических свойств ФК с симметрией его кристаллической решетки может быть существенно иной по сравнению с обычными кристаллами. В частности, ФК кубической симметрии, в отличие от своих симметрийных аналогов из класса обычных кристаллов, могут демонстрировать заметные эффекты оптической анизотропии [5].

В настоящей работе исследованы спектры брэгговского отражения света от опалоподобных ФК (относящихся к классу симметрии $\mathrm{O}_{\mathrm{h}}$ ) в зависимости от ориентации плоскости падения относительно кристаллографических

\footnotetext{
* Доклад на XIV Международной конференции „Физика диэлектриков“" (Санкт-Петербург, 29 мая-2 июня 2017 г.).

Материалы конференции частично опубликованы в выпуске № 3 за 2018 г. журнала „Физика твердого тела“.
}

осей ФК. В качестве объектов экспериментального изучения использовались полимерные ФК, изготовленные из частиц полистирола. Основное внимание обращено на эффект узкополосной оптической анизотропии ФК, проявляющийся в виде резонансного усиления отраженного сигнала в скрещенных состояниях поляризатора и анализатора $(p-s$ или $s-p$ конфигурации). Данные измерений сопоставлены с теоретическими расчетами, выполненными в рамках динамической теории многоволновой дифракции света применительно к ФК [6].

\section{2. Эксперимент}

Исследованные нами образцы опалоподобных ФК представляли собой пленки (толщиной около $5 \mu \mathrm{m}$ ), сформированные из монодисперсных частиц полистирола в виде глобул диаметром $\sim 280 \mathrm{~nm}$. Тонкие пленки получали путем нанесения капли дисперсии капли (сухой остаток - 1\%) объемом 150-200 $\mu$ 1 на покровные стекла, предварительно обезжиренные хромовой смесью. Стекла помещали на выверенный по уровню горизонтальный предметный столик. Водные дисперсии латексов высыхали при температуре $55-60^{\circ} \mathrm{C}$ в течение 15-20 min. Частицы полистирола синтезировали методом безэмульгаторной эмульсионной сополимеризации стирола с метакриловой кислотой под действием персульфата калия [7-9]. При этом в поверхностном слое частиц локализуются полимерные цепи, обогащенные звеньями метакриловой кислоты, степень ионизации карбоксильных групп которых и, следовательно, поверхностный заряд, варьировали путем изменения рН 
дисперсионной среды, что позволило оптимизировать условия формирования полимерных ФК [7].

Спектры брэгговского отражения света изучались на установке, собранной на базе спектрометра МДР-23 (рабочий спектральный диапазон 400-850 nm, обратная линейная дисперсия $1.3 \mathrm{~nm} / \mathrm{mm})$. В качестве источника белого света служила лампа накаливания, луч от которой коллимировался с помощью диафрагм и линз таким образом, что угол сходимости пучка не превышал $3^{\circ}$. Световой пучок направлялся на образец, закрепленный на гониометре из комплекта поставки эллипсометра ЛЭФ-3М. Ориентация образца относительно плоскости падения-отражения света осуществлялась путем контролируемого (с точностью до $1^{\circ}$ ) азимутального вращения ФК-пленки в вертикальной плоскости, перпендикулярной плоскости падения и совпадающей с отражающей поверхностью образца (111). Отраженный от поверхности образца свет через систему линз направлялся на входную щель спектрометра, ширина которой варьировалась в пределах 100-200 $\mu \mathrm{m}$. Световой поток на выходе спектрометра регистрировался с помощью фотоэлектронного умножителя ФЭУ-79 в режиме счета фотонов, электрический сигнал после прохождения через предусилитель и блок сопряжения обрабатывался компьютером, а записанный спектр в цифровом виде сохранялся в файле.

Спектры отражения регистрировались в поляризованном свете в конфигурациях анализатора-поляризатора $s-s, p-p, p-s$ и $s-p$ при разных углах падения $\theta$. При этом азимутальная ориентация образца менялась в соответствии с геометрией рис. 1 (т.е. в эксперименте азимутальный угол $\varphi$ отсчитывался от плоскости, перпендикулярной системе наклонных кристаллических

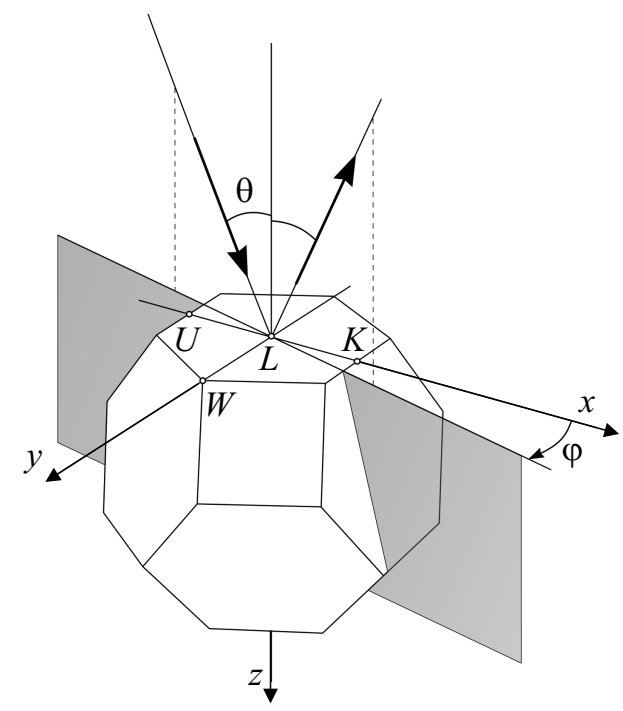

Pис. 1. Геометрия отражения света от опалоподобного ФК: $\theta-$ угол падения, $\varphi-$ азимут плоскости падения, отсчитываемый от базисной плоскости, перпендикулярной наклонным кристаллическим плоскостям $(1,1, \overline{1})$.

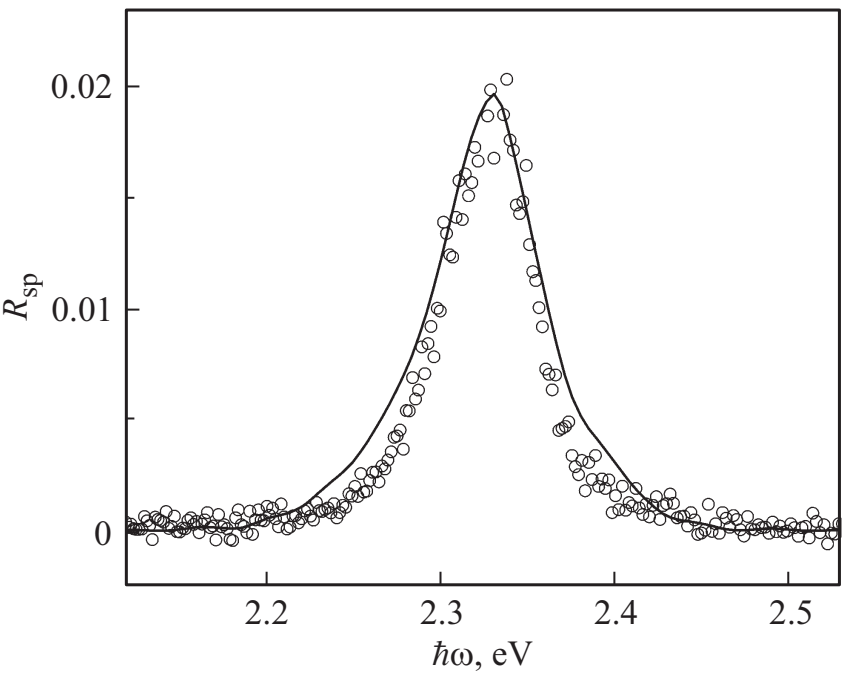

Рис. 2. Спектр брэгговского отражения света от опалоподобного полимерного ФК в конфигурации анализатора-поляризатора $s-p$ при угле падения $\theta=56^{\circ}$ и азимуте плоскости падения $\varphi=15^{\circ}$. Точки - эксперимент, сплошная кривая теоретический расчет.

плоскостей $(1,1, \overline{1}))$. Ориентация образца, соответствующая значению $\varphi=0^{\circ}$, контролировалась с помощью сканирующего электронного микроскопа. Более точно такая ориентация устанавливалась предложенным нами ранее методом [10], основанным на анализе спектров брэгговского отражения в $s-s$ конфигурации поляризатора-анализатора.

На рис. 2 (экспериментальные точки) представлен спектр $R_{S P}$ брэгговского отражения света от исследуемого ФК, измеренный в $s-p$ конфигурации анализатораполяризатора при угле падения $\theta=56^{\circ}$ и азимутальной ориентации образца $\varphi=15^{\circ}$. Сравнение изображенного на рис. 2 спектра со спектром отражения $R_{S S}$, измеренным при тех же значениях углов $\theta$ и $\varphi$, показало, что максимум коэффициента отражения $R_{S P}$ формируется в той спектральной области, где наиболее существенны эффекты многоволновой дифракции света [6]. Поэтому естественно связать возникновение заметного сигнала $R_{S P}$ в выбранной конфигурации отражения света с проявлением многоволновой дифракции.

Коэффициент отражения $R_{S P}$ практически равен нулю при любых значениях угла падения $\theta$, если плоскость падения света перпендикулярна одновременно системам латеральных $(1,1,1)$ и наклонных $(1,1, \overline{1})$ кристаллических плоскостей (рис. 1, азимут плоскости падения $\left.\varphi=0^{\circ}\right)$. Сигнал в скрещенных, $p-s$ и $s-p$, состояниях анализатора-поляризатора также отсутствует, когда угол $\varphi$ кратен $60^{\circ}$. Однако при промежуточных значениях $\varphi$ в небольшом интервале углов падения вблизи $\theta \approx 55^{\circ}$ в спектрах $R_{P S}$ и $R_{S P}$ „недиагональных“ коэффициентов отражения обнаруживается узкий пик отражения, свидетельствующий об оптической анизотропии ФК. Наиболее интенсивный кросс-поляризационный 

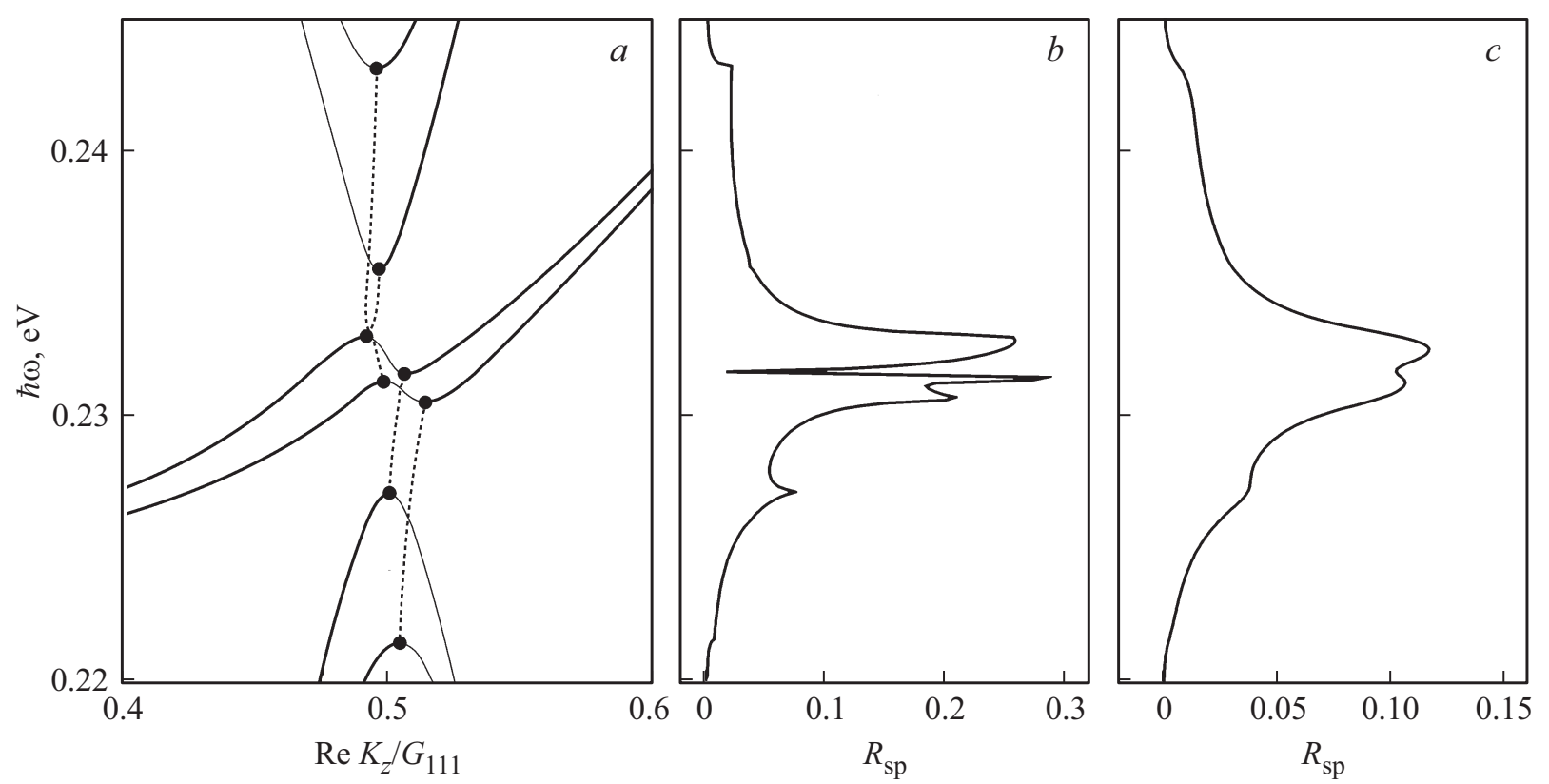

Рис. 3. Сопоставление энергетического спектра электромагнитных мод $(a)$ полуограниченного опалоподобного ФК с рассчитанными спектрами недиагональных коэффициентов отражения $R_{S P}$ при константах затухания $\Gamma=0 \mathrm{meV}(b)$ и $\Gamma=13 \mathrm{meV}(c)$; угол падения $\theta=56^{\circ}$, азимут плоскости падения $\varphi=15^{\circ}$.

сигнал регистрируется при азимутальной ориентации образца вблизи $\varphi \approx 15^{\circ}$.

В связи с представленными на рис. 2 экспериментальными данными следует отметить, что измеряемый сигнал $R_{S P}$ формируется на довольно заметном по отношению к пику отражения фоне рассеянного света, достигающем значения порядка $1 \%$ от интенсивности падающего света (на рис. 2 этот фон вычтен из спектра). Такой фон, по-видимому, указывает на определенную степень структурной неупорядоченности образца, связанной с технологией приготовления ФК пленок.

\section{3. Теория и обсуждение результатов}

Как следует из результатов наших предыдущих исследований [6], посвященных изучению механизмов формирования брэгговских спектров отражения света от фотонных кристаллов, принципиальные детали таких спектров могут быть описаны не только качественно, но и с хорошей точностью количественно, в рамках динамической теории многоволновой дифракции света. Суть подхода заключается в выделении в разложении напряженности электрического поля $\mathbf{E}_{\mathbf{K}}(\mathbf{r})$ блоховской моды по векторам $\mathbf{G}$ обратной решетки тех слагаемых, которые дают преобладающий вклад в дифракцию света в исследуемой области спектра. В рассматриваемом нами случае

$$
\mathbf{E}_{\mathbf{K}}(\mathbf{r})=\sum_{h k l} \mathbf{A}_{\mathbf{K}-\mathbf{G}_{h k l}} e^{j\left(\mathbf{K}-\mathbf{G}_{h k l}\right) \cdot \mathbf{r}},
$$

где $\mathbf{K}$ - волновой вектор моды, $\mathbf{A}_{\mathbf{K}-\mathbf{G}_{h k l}}-$ не зависящие от пространственных координат $\mathbf{r}$ амплитуды, $(h k l)-$ индексы кристаллических плоскостей, которые принимают значения $(0,0,0),(1,1, \pm 1),(0,2,0)$. Тогда пространственный профиль диэлектрической функции $\varepsilon(\mathbf{r})$ кристалла следует задавать разложением

$$
\varepsilon(\mathbf{r})=\sum_{h k l} \varepsilon_{h k l} e^{j \mathbf{G}_{h k l} \mathbf{r}}+c . c .,
$$

включающим в себя соответствующие пространственные гармоники с фурье-амплитудами $\varepsilon_{h k l}$. Численные значения коэффициентов $\left|\varepsilon_{h k l}\right|$ рассчитываются на основании полученных экспериментально средней диэлектрической проницаемости $\varepsilon_{0} \equiv \varepsilon_{000}$ ФК-среды и фактора заполнения $f$ материала ФК структурными элементами (в данном случае частицами полистирола с диэлектрической проницаемостью $\varepsilon_{a}=2.555$ [11] на длине волны $\lambda=532 \mathrm{~nm})$. Для исследованного образца $\varepsilon_{0}=2.186$, $f=0.78$.

На рис. 3, $а$ изображен рассчитанный энергетический спектр собственных мод, формируемых в полуограниченном ФК в геометрии отражения рис. 1 при угле падения $\theta=56^{\circ}$ и азимутальной ориентации плоскости падения $\varphi=15^{\circ}$. Энергетический спектр построен для модели идеального, структурно упорядоченного ФК. Участки дисперсионных кривых, выделенные сплошными жирными линиями, соответствуют электромагнитным состояниям с положительными значениями проекции групповой скорости $v_{z}=\partial \omega / \partial K_{z}$ на внутреннюю нормаль к поверхности кристалла (считается, что ось $z$ декартовой системы координат направлена вдоль этой нормали). Именно такие моды с $v_{z}>0$ участвуют в распространении света вглубь полубесконечной среды. 
Моды $\mathrm{c} v_{z}<0$, обозначенные тонкими сплошными линиями, могут возбуждаться только в случае ФК-пластинки конечной толщины, когда существенно отражение от задней грани пластинки (в этой связи см. [12]). Пунктирные кривые на рис. 3, c, соединяющие точки экстремумов, помеченные жирными точками, также представляют собой решения дисперсионного уравнения. Однако эти решения соответствуют эванесцентным модам, локализованным вблизи внутренней поверхности ФК. Такие моды характеризуются комплексными значениями волнового вектора К (на рисунке, ради простоты, изображены только вещественные части $z$-проекций $\mathbf{K})$.

Дисперсионные кривые рис. 3, a говорят о том, что внутри ФК осуществляется многомодовый характер распространения света: на каждой частоте $\omega$ внешнего света в непосредственной области брэгговского резонанса может возбуждаться, по крайней мере, 6 мод (если речь идет о полубесконечной среде или достаточно толстой ФК-пластинке). Ситуация в определенном смысле ассоциируется с эффектами в кристаллооптике с учетом пространственной дисперсии, когда речь идет о добавочных [1] световых волнах.

В реальных образцах ФК заметную роль могут играть процессы затухания электромагнитных состояний, связанные с дополнительным упругим рассеянием света и поглощением энергии. Такого рода затухание (экстинкцию) можно феноменологически учесть в дисперсионных уравнениях собственных электромагнитных мод, вводя мнимую добавку $i \cdot \Gamma / 2$ к частоте $\omega$. Тогда величина $\tau \equiv 1 / \Gamma$ играет роль времени жизни электромагнитной моды ФК. Такой подход для описания затухания в области брэгговских резонансов ФК представляется более ясным с физической точки зрения по сравнению с формальным введением [10] мнимой добавки $i \varepsilon_{0}^{\prime \prime}$ к средней диэлектрической проницаемости $\varepsilon_{0}$. В связи с этим, отметим, что по порядку величины $\varepsilon_{0}^{\prime \prime} \approx \varepsilon_{0} \Gamma / \omega_{0}$, где $\omega_{0}-$ характерная частота брэгговского резонанса.

Теоретические спектры $R_{S P}$ брэгговского отражения света рассчитывались в рамках подхода [13] (впервые предложенного в [14]), обобщенного в настоящей работе на случай, когда $T E$ - и $T M$-классификация собственных мод теряет смысл. Рассчитанные для выше указанных углов $\theta$ и $\varphi$ спектры отражения при значениях $\Gamma=0$ и $\Gamma=13 \mathrm{meV}$ представлены на рис. $3, b$ и $3, c$ соответственно.

В идеальном случае, когда $\Gamma=0$, спектр отражения $R_{S P}$ содержит спектральные особенности в виде резких пиков и провалов. Из сопоставления этого спектра с соответствующими дисперсионными кривыми собственных мод (рис. 3,a) видно, что особенности в спектрах проявляются вблизи пороговых частот, на которых групповая скорость мод обращается в ноль и в перенос энергии включаются дополнительные каналы рассеяния (ср. с общими утверждениями о возникновении спектральных особенностей разного типа в сечении многоканального рассеяния [15]).
С увеличением $\Gamma$ (рис. 3,c) резкие особенности в спектре $R_{S P}$ постепенно сглаживаются и при значении $\Gamma=50 \mathrm{meV}$, позволяющем воспроизвести экспериментальный спектр рис. 2 (эксперимент - точки, расчет сплошная линия), кривая отражения $R_{S P}$ выглядит в виде практически симметричного контура с максимумом.

Следует отметить, что полуширина теоретического контура отражения при достаточно больших значениях параметра Г оказывается близкой к вводимому в расчет значению Г, что, в частности, демонстрирует рис. 2. Поскольку экспериментальный контур отражения $R_{S P}$ хорошо совпадает с теоретическим, то для оценки времени жизни $\tau$ электромагнитной моды в ФК можно использовать простое измерение полуширины наблюдаемого контура отражения. В случае исследованного нами образца ФК получаем значение $\tau \approx 0.08 \mathrm{ps}$.

Анализ измеренных спектров отражения в $s-s$ и $p-p$ конфигурациях эксперимента, как правило [10], указывает также на незначительную одноосную деформацию образцов в кристаллографическом направлении, перпендикулярном поверхности ФК-пленки. Однако такая деформация в силу симметрийных соображений сама по себе не может быть причиной появления сигнала отражения $R_{S P}$. Поэтому выводы, которые мы делаем в настоящей работе, относятся и к недеформированным кубическим ФК-структурам.

\section{4. Заключение}

Полученные нами результаты показывают, что несмотря на высокую симметрию опалоподобных фотонных кристаллов, их оптические свойства обладают сильной анизотропией, что выражается особенно ярко в условиях многоволновой брэгговской дифракции. При азимутальной ориентации плоскости падения, которая не соответствует наиболее симметричным направлениям распространения света в ФК (угол $\varphi$ не кратен $60^{\circ}$ ), собственные моды электромагнитного поля становятся эллиптически поляризованными и $T E, T M$-классификация таких мод теряет смысл. В результате при $p$ или $s$-поляризации падающего луча отраженный свет приобретает эллиптическую поляризацию, что проявляется экспериментально в виде резонансного сигнала отражения в скрещенных состояниях поляризатора и анализатора. Таким образом, можно заключить, что обсуждаемый эффект представляет собой новое, специфическое проявление многоволновой брэгговской дифракции в трехмерных фотонных кристаллах.

\section{Список литературы}

[1] В.М. Агранович, В.Л. Гинзбург. Кристаллооптика с учетом пространственной дисперсии и теория экситонов. Наука, M. (1979). 432 c.

[2] Е.Ф. Гросс, А.А. Каплянский. ДАН СССР 132, 98 (1960). 
[3] J.F. Galisteo-López, M. Ibisate, R. Sapienza, L.S. Froufe-Pérez, Á. Blanco, C. López. Adv. Matter. 23, 30 (2011).

[4] Optical Properties of Photonic Structures: Interplay of Order and Disorder / Eds M.F. Limonov, R.M. De La Rue. CRC Press, Boca Raton, FL, USA (2012). 566 p.

[5] С.Г. Романов. ФТТ 52, 788 (2010).

[6] V.G. Fedotov, A.V. Sel'kin, T.A. Ukleev, A.Yu. Men'shikova, N.N. Shevchenko. Phys. Status Solidi B 248, 2175 (2011).

[7] A.Yu. Menshikova, B.M. Shabsels, N.N. Shevchenko, A.G. Bazhenova, A.B. Pevtsov, A.V. Sel'kin, A.Yu. Bilibin. Colloids Surf. A 298, 27 (2007).

[8] А.Ю. Меньшикова, Н.Н. Шевченко, И.В. Бугаков, А.В. Якиманский, А.В. Селькин. ФТТ 53, 1091 (2011).

[9] Н.Н. Шевченко, Б.М. Шабсельс, А.Ю. Меньшикова, Г.А. Панкова, Р.Ю. Смыслов, Н.Н. Сапрыкина, А.В. Селькин, Т.А. Уклеев. Российские нанотехнологии 7, 105 (2012).

[10] А.Г. Баженова, А.В. Селькин, А.Ю. Меньшикова, Н.Н. Шевченко. ФТТ 49, 2010 (2007).

[11] А.П.Бабичев, Н.А. Бабушкина, А.М. Братковский и др. Физические величины: Справочник / Под ред. И.С. Григорьева, Е.3. Мейлихова. Энергоатомиздат, М. (1991). C. 785 .

[12] В.Г. Федотов, А.В. Селькин. ФТТ 53, 1077 (2011).

[13] V.G. Fedotov, T.A. Ukleev, A.Yu. Men'shikova, N.N. Shevchenko, A.V. Sel'kin. Proc. of SPIE 8425, 1 (2012).

[14] A.V. Sel'kin. In: Proc. of $12^{\text {th }}$ Int. Symp. Nanostructures: Physics and Technology. Ioffe Institute, SPb (2004). p. 111.

[15] Л.Д. Ландау, Е.М. Лифшиц. Квантовая механика. ФИЗМАТЛИТ, М. (2004). С. 745. 